\title{
A Governança no APL do Açaí no Município de Igarapé-Miri e sua Implicação para o Desenvolvimento Local
}

\author{
http://dx.doi.org/10.21527/2237-6453.2020.54.234-249
}

Recebido em: 10/9/2019

Aceito em: $27 / 10 / 2020$

Francisco de Paulo Coelho Junior ${ }^{1}$, Fábio Carlos da Silva²

\begin{abstract}
RESUMO
Práticas de desenvolvimento local com bases endógenas são capazes de transformar territórios em unidades produtivas propulsoras de avanços socioeconômicos. Iniciativas assim podem ser construídas a partir do estabelecimento de formas de governança moldadas pela criação de laços de interação e mecanismos de coordenação. Nesse sentido, este artigo apresenta a caracterização e as inter-relações dos agentes do Arranjo Produtivo Local - APL - do açaí no município paraense de Igarapé-Miri e a definição do tipo de governança existente no Arranjo. Para alcance do objetivo proposto, desenvolveu-se pesquisa do tipo teórica e de campo, de caráter qualitativo e descritivo, que contou com o auxílio de fontes bibliográficas e entrevistas. Os resultados obtidos mostram como os agentesse inter-relacionam no APL, como a governança exercida está estruturada atualmente e quais as implicações disto para o desenvolvimento local no município.
\end{abstract}

Palavras-chave: Arranjo Produtivo Local. Desenvolvimento Local. Governança.

GOVERNANCE IN THE APL OF AÇAÍ IN THE MUNICIPALITY OF IGARAPÉ-MIRI AND ITS IMPLICATION FOR LOCAL DEVELOPMENT

\section{ABSTRACT}

Local development practices with endogenous bases are capable of transforming territories into productive units that propel socioeconomic advances. Such initiatives can be built on the establishment of forms of governance shaped by the creation of interaction bonds and coordination mechanisms. In this sense, this article presents: the characterization and interrelations of the agents of the Local Productive Arrangement - APL - of the açaí in the municipality of Igarapé-Miri and the definition of the type of governance existing in the Arrangement. In order to reach the proposed objective, a qualitative and descriptive research of the theoretical and field type was developed, with the aid of bibliographical sources and interviews. The results show how the agents interrelate in the APL, how governance is currently structured and what implications for local development in the municipality.

Keywords: Local Productive Arrangement. Local Development. Governance.

\footnotetext{
${ }^{1}$ Autor correspondente. Universidade Federal do Pará (Ufpa). Rua Augusto Côrrea, 01 - Guamá. CEP 66073-044 - Belém/PA, Brasil. http:// lattes.cnpq.br/5151272206614710. https://orcid.org/0000-0003-3612-7903. franciscocj@ufpa.br

2 Universidade Federal do Pará (Ufpa). Belém/PA, Brasil.
} 
A partir da segunda metade da década de 80 do século 20, novas políticas de desenvolvimento objetivavam ajustar o sistema produtivo brasileiro, abrindo caminhos para proposições de crescimento econômico e social com viés descentralizador. Alinhada a isto, objetivando influenciar os processos de crescimento das economias intra-regionais, a política de desenvolvimento local ganhou campo como um modelo desenvolvimentista responsável por superar os desequilíbrios econômicos a partir do fomento a territórios com potencialidades de desenvolvimento competitivo capaz de tirar proveito do potencial existente (BARQUERO, 2002). Nessa direção, e como forma de viabilizar o desenvolvimento local, surgiu o termo governança, conceituado por Gonçalves (2006) como "ação conjunta de Estado e sociedade na busca de soluções e resultados para problemas comuns".

Nesse viés, o município paraense de Igarapé-Miri, localizado na região do Baixo Tocantins, despontou no início dos anos 90 do século 20 ao aplicar as bases teóricas do desenvolvimento local endógeno, pondo em prática um projeto de crescimento econômico denominado Mutirão que contou com a participação ativa, organizada e democrática da população diretamente envolvida, ao investir na cultura de cultivo do açaí por intermédio de práticas de manejo sustentável de áreas degradadas, preocupando-se essencialmente com o bem-estar da população local e com a conservação do meio ambiente.

Consequentemente, Igarapé-Miri tornou-se um expressivo produtor de açaí, por meio da criação de bases sólidas que possibilitaram significativo processo de mudança estrutural no cenário econômico local, dada a presença de um aglomerado de agentes que se inter-relacionam em torno da atividade produtiva do fruto, desenvolvendo relações econômicas e não econômicas entre si, trocando conhecimentos e partilhando mecanismos de governança (CASSIOLATO; LASTRES, 2003b).

Por isso, a questão central desta pesquisa centra-se em: a) caracterizar a inter-relação entre os agentes do APL; b) analisar a estrutura e definir o tipo de governança existente no APL do açaí em Igarapé-Miri e suas implicações para o desenvolvimento local no município.

\section{ÁREA DE ESTUDO}

O município de Igarapé-Miri, localizado na margem direita do rio homônimo, pertence à zona fisiográfica Guajarina, mesorregião do Baixo Tocantins, no estado do Pará. Com uma extensão territorial de $1.996 .790 \mathrm{~km}^{2}$, o município constitui-se numa vasta área recortada por rios, furos, igarapés e ilhas fluviais, onde dois grandes ecossistemas são encontrados: as áreas de terra firme e de várzea. Na terra firme, a vegetação é mista, com presença de extensas áreas de floresta tropical e áreas modificadas pela ação humana para fins agrícolas e pecuários. Nas áreas de várzea, a floresta tropical é abarrotada de vegetais ombrófilos - cujo desenvolvimento exige clima chuvoso e alagado ou deles se beneficiam. Esta geografia é característica de toda a região do estuário próximo à foz do Rio Tocantins, local propício para o cultivo do açaí. 
Figura 1 - Mapa de localização do município de Igarapé-Miri/PA

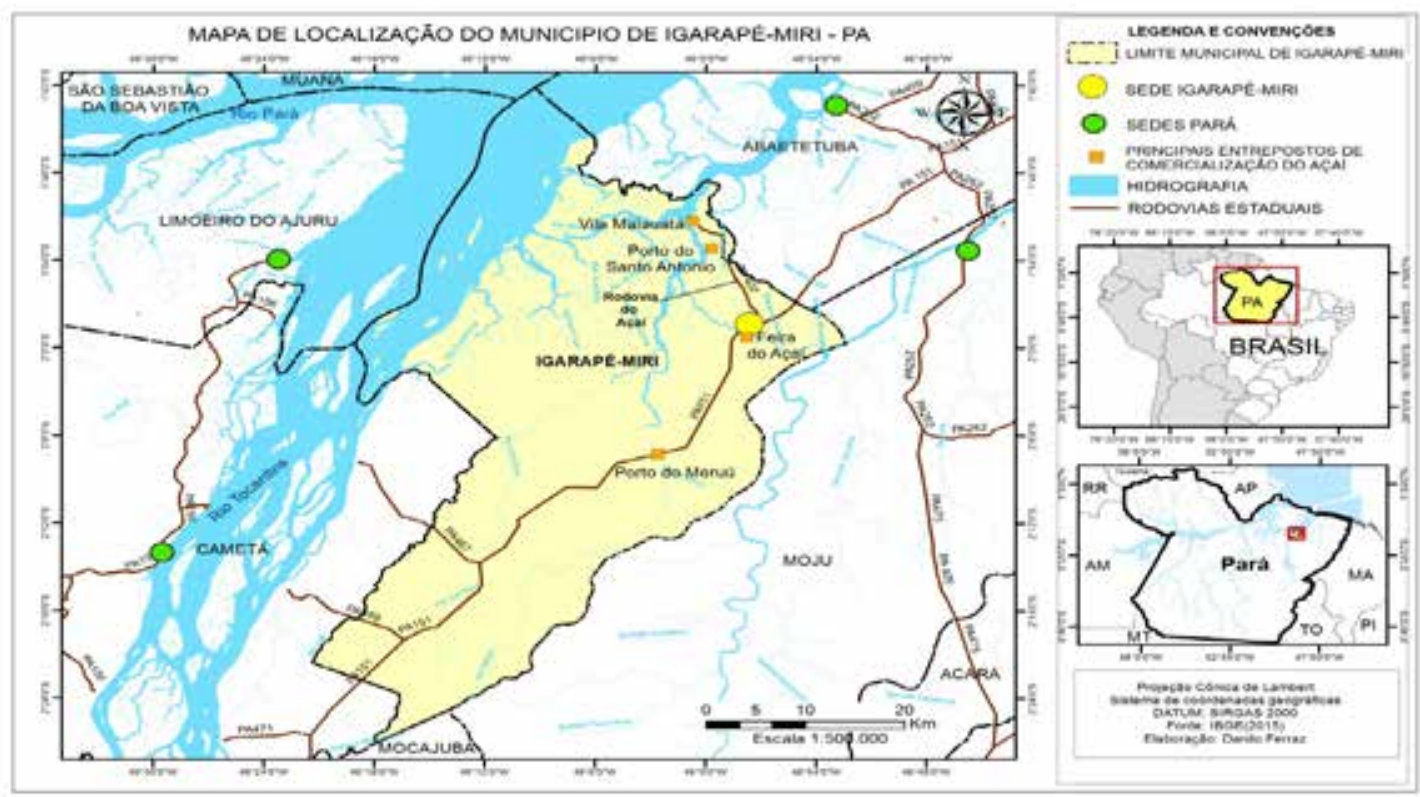

Fonte: Elaborado pelos autores.

\section{DESENVOLVIMENTO LOCAL ENDÓGENO}

A teoria endogenista tem como proposição coligar fatores de produção intrarregionais críticos - como o capital social, o capital humano, o conhecimento, a pesquisa e o desenvolvimento, a informação e as instituições - com o desenvolvimento, dispensando a abordagem exógena de desenvolvimento, bastante praticada até final da década de 1970. Esta teoria fundamenta-se na premissa de que toda região dotada dos fatores supracitados está estrategicamente direcionada para desenvolvê-los internamente e, por isso, possui as melhores condições de atingir um desenvolvimento acelerado e equilibrado (SOUZA FILHO, 2002).

Segundo D'ascenzi e Lima (2019), o conceito de endogeneidade fundamenta a ideia de mudança social intencional a partir de características culturais e setoriais locais. Essa concepção abriu caminhos para novas proposições desenvolvimentistas, "momento em que os atores locais e regionais passaram a empreender ações objetivando influenciar os processos de crescimento das economias locais" (BARQUERO, 2002, p. 25). Por isso, o diferencial deste modelo está no fato de que esta proposta passa a ser estruturada a partir dos próprios atores locais, e não mais pelo planejamento centralizado, exógeno, de cima para baixo (TENÒRIO, 2007).

Portanto, segundo Buarque (2002, p. 25), "o desenvolvimento local pode ser conceituado como um processo endógeno de mudança, que leva ao dinamismo econômico e à melhoria da qualidade de vida da população em pequenas unidades territoriais e agrupamentos humanos".

Embasado nessas questões, com foco em sistemas produtivos, o desenvolvimento endógeno surge como uma estratégia em que comunidades, através de suas identidades próprias, tomam iniciativas visando assegurar o desenvolvimento através do fortalecimento de suas capacidades organizacionais, criando condições de desenvolver potencialidades regionais próprias sem a dependência de fatores exógenos. Este modelo estimula o em- 
preendedorismo local, podendo ser visto como um "processo de crescimento econômico e de mudança estrutural, liderado pela comunidade local ao utilizar seu potencial de desenvolvimento, que leva à melhoria do nível de vida da população" (BARQUERO, 2002, p. 41).

\section{ARRANJOS PRODUTIVOS LOCAIS (APLS)}

Entre as formas encontradas para alavancagem desenvolvimentista endógena, destaca-se a abordagem em Arranjos Produtivos Locais (APLs), evidenciada por estabelecer uma nova perspectiva de estímulo ao desenvolvimento econômico com viés regional, descentralizado e com foco nas vantagens competitivas regionais. Na visão de Apolinário e Silva (2008), o conceito de APL tem se destacado como uma importante estratégia para promover e orientar o desenvolvimento local/regional e gerar ocupação e renda no país, através de "vínculos expressivos de articulação, interação, cooperação e aprendizagem" (BOTELHO; CAMPOS, 2009, p. 16).

Sobre APL, a Rede de Pesquisa em Sistemas Produtivos e Inovativos Locais - RedeSist adota uma definição amplamente difundida e adotada no Brasil, conceituando que "arranjos produtivos locais são aglomerações territoriais de agentes econômicos, políticos e sociais - com foco em um conjunto específico de atividades econômicas - que apresentam vínculos mesmo que incipientes" (CASSIOLATO; LASTRES, 2003a, p. 5). O argumento básico do conceito analítico apontado pela RedeSist, segundo Cassiolato e Latres (2003a), é que, salvo algumas exceções, onde "houver produção de qualquer bem ou serviço haverá sempre um arranjo em seu torno, envolvendo atividades e atores relacionados à sua comercialização, assim como à aquisição de matérias-primas, máquinas e demais insumos". Ainda para estes autores, "tais arranjos variarão desde aqueles mais rudimentares àqueles mais complexos e articulados" (CASSIOLATO; LASTRES, 2003a, p. 8).

Costa $(2010$, p. 27) vai mais além ao destacar que o termo APL remete à

concentração de quaisquer atividades similares ou interdependentes no espaço não importando [...] a natureza da atividade econômica desenvolvida, podendo esta pertencer ao setor primário, secundário ou até mesmo terciário, variando desde estruturas artesanais com pequeno dinamismo, até arranjos que comportem grande divisão do trabalho.

Antero et al. (2016) destacam, contudo, que em um APL também podem ser identificados desafios relativos à condução e organização de ações conjuntas, que requerem a identificação de opções para facilitar a atuação dos atores envolvidos.

Diante disso, a consolidação de sólidas estruturas de governança é fundamental para a perenidade de APLs por meio de iniciativas que promovam o alcance de objetivos, a fim de permitir o desenvolvimento do território mediante ações coletivas ou individuais, desde que sejam harmônicas.

\section{GOVERNANÇA NO CONTEXTO DO DESENVOLVIMENTO LOCAL ENDÓGENO}

Mencionado pela primeira vez na década de 80 do século 20 nos relatórios do Banco Mundial como "sinônimo de bom governo" (MATOS; DIAS, 2013, p. 23), o termo governança, após incorporar outras variáveis, aponta para um novo modo de governar caracterizado pelo 
[...] maior grau de interação e de cooperação entre o Estado e atores não estatais que constituem redes de decisão conjuntas [...]. Assim o processo de formulação e implantação de políticas públicas deve ocorrer através da cooperação inter e intrainstitucional, e entre os atores públicos e privados, numa estrutura de redes e não mais de autoridade hierárquica (CAMPOS, 2002).

Mesmo que Gonçalves (2006) afirme que o termo governança tem aplicação em variados campos e possui sentidos diferentes, inúmeros estudiosos no assunto, ao abordarem o tema, apresentam conceitos convergentes sobre o mesmo quando trazem à baila a aplicação do termo de forma qualitativa, coadunando com o entendimento de que

A governança é determinada pela descentralização da autoridade e das funções ligadas ao ato de governar, bem como pela parceria ou ação conjunta entre o público e o privado, o Estado e a sociedade civil ou governantes e governados, através do estabelecimento de ações conjuntas de redes organizadas, gestão das interações, sistemas de regulação, mecanismos de coordenação e negociação entre atores sociais, visando uma solução inovadora dos problemas comuns, criando possibilidades e chances de um desenvolvimento futuro sustentável para todos os participantes (CASSIOLATO; LASTRES, 2003b; LOFFER, 2001 apud KISSLER; HEIDEMANN, 2006; GONÇALVES, 2006).

Diante das definições postas até aqui, compreende-se que só existe governança quando há gestão descentralizada ou compartilhada dos processos decisórios, com participação de diversos agentes - atores sociais, organizações públicas e privadas, redes de cooperação formais e informais e o sistema institucional construído por estas - com capacidade de articularem-se em rede, viabilizando estratégias de desenvolvimento orientadas para resultados de forma colaborativa, no intuito de criar bases sólidas que possibilitem a geração de valor para o desenvolvimento de todos os envolvidos. Isto posto, cabe ratificar o entendimento mencionando Gonçalves (2006), que defende que "o surgimento dos atores não-estatais é central para o desenvolvimento da ideia e da prática da governança".

Segundo Tapia (2005), a reprodução dos modelos de desenvolvimento local depende de estruturas de governança resultantes da ação coletiva de um sistema de atores que interage dentro de um contexto espacial, institucional, político e cultural específico. Por isso, é preciso compreender que tais estruturas pertencem a um processo complexo que depende de diferentes níveis de cooperação (FUINI, 2014).

Por esse motivo, a conjuntura institucional de um APL faz referência à estruturação existente nele, levando em consideração a atuação e a articulação dos agentes ou entidades no exercício de seus propósitos, ponderando suas capacidades políticas, econômicas e sociais, além dos recursos disponíveis.

\section{Tipos de Governança}

A caracterização da governança pode ser observada por meio de algumas considerações teórico-metodológicas realizadas por diversos autores que se dedicaram a estudar a definição desta pela análise de suas bases estruturais definidas pelo modo de atuação e articulação dos agentes. Nesse rumo, as contribuições de Colletis et al. (1999) podem ser facilmente aplicadas em APLs, posto que estes ressaltam que, a partir da 
articulação dos atores-chave com os mecanismos regulatórios globais, forma-se uma dinâmica territorial que se traduz na natureza da governança local, permitindo propor caracterizações mais precisas das estruturas instituídas no APL.

Colletis et al. (1999) apresentam quatro tipos de governança observados por intermédio do caráter público ou privado, dos objetivos atribuídos e dos modos como os atores se apropriam dos recursos territoriais assim produzidos. São eles: privada, privada-coletiva, pública e mista, apresentados sinteticamente na Tabela 1.

Tabela 1 - Estilos de Governança

\begin{tabular}{l|l}
\hline TIPOS & DEFINIÇÃO \\
\hline Governança privada & $\begin{array}{l}\text { Ocorre quando um ator ou grupo privado domina e coordena os re- } \\
\text { cursos de acordo com seu objetivo. }\end{array}$ \\
\hline $\begin{array}{l}\text { Governança } \\
\text { privada-coletiva }\end{array}$ & $\begin{array}{l}\text { Ocorre quando um conjunto de atores privados, representados por } \\
\text { uma instituição formal, coordena suas estratégias para alcance de ob- } \\
\text { jetivos comuns a estes. }\end{array}$ \\
\hline Governança pública & $\begin{array}{l}\text { Ocorre quando instituições públicas produzem bens ou serviços cole- } \\
\text { tivos a serem usufruídos por todos os atores, indiscriminadamente. }\end{array}$ \\
\hline Governança mista & $\begin{array}{l}\text { Ocorre quando há a associação dos demais tipos de governança, mas } \\
\text { com uma dominante. }\end{array}$ \\
\hline
\end{tabular}

Fonte: Adaptada de Colletis et al. (1999).

Os possíveis formatos da governança, apontados por Colletis et al. (1999), possibilitam configurar a dinâmica do APL ao definir o modo como os agentes atuam no mesmo. A partir desta teoria, conclui-se que o tipo de governança depende fundamentalmente de dois fatores: atuação governamental, pela instituição de políticas públicas que enganjem os atores sociais, e as estratégias mercadológicas dos agentes econômicos no Arranjo. Esta conclusão fundamenta-se a partir do entendimento de que a governança pública nada mais é do que um reflexo de efetiva e significativa atuação do poder público no APL, a ponto de, por meio de suas próprias ações, condicionar o comportamento dos demais agentes atuantes no arranjo, seja mediante obras, incentivos fiscais, leis, etc. Por outro lado, as governanças privada e privada-coletiva demonstram como organizações, individualmente ou em conjunto, utilizam estrategicamente seus recursos (ativos) para obter vantagem em suas transações comerciais sobre os demais agentes.

\section{PROCEDIMENTOS METODOLÓGICOS}

Quanto aos objetivos, esta pesquisa foi de natureza exploratória e descritiva. 0 caráter exploratório levou-nos a adotar a aplicação de pesquisa bibliográfica como técnica de coleta de dados secundários que foram adquiridos por meio de pesquisa em estudos acadêmicos que abordam a mesma problemática ou fazem referência ao mesmo objeto de estudo abordado, planos de desenvolvimento regionais e locais voltados para a cultura do açaí e índices sociais e econômicos. Quanto ao método descritivo, foram analisadas, a partir de dados primários, as principais características, fatos, atitudes e relações de agentes que atuam no APL, de maneira a demonstrar com mais clareza os fenômenos relacionados com a situação-problema. 
A análise da estrutura que define o tipo de governança existente atualmente no Arranjo, foi possível em virtude da aplicação de roteiro de entrevistas contendo perguntas semiabertas, direcionadas a representações públicas e privadas atuantes diretamente no APL do açaí no município de Igarapé-Miri, totalizando o número de cinco: Prefeitura, representada pelo Departamento de Agricultura, STR, Codemi, Indústria Açaí Miriense e um ex-prefeito que atua como produtor rural do município.

Com relação à abordagem, a pesquisa foi definida como qualitativa, tendo em conta que envolveu a obtenção e interpretação dos dados, dando ênfase ao processo comportamental dos agentes do APL, o que possibilitou analisar as inter-relações destes.

Os dados primários coletados foram analisados mediante a técnica de Análise de Conteúdo, descrita por Bardin (1977, p. 38) como "conjunto de técnicas de análise das comunicações, que utiliza procedimentos sistemáticos e objectivos de descrição do conteúdo das mensagens". Para isso, o conteúdo coletado foi analisado por meio da decodificação qualitativa dos dados coletados nas entrevistas, com descrições fundadas em textos e objetivando demonstrar a realidade do objeto de estudo, mais precisamente a dinâmica e a complexidade econômica, política e social existente no Arranjo, responsável por definir as relações contratuais, de confiança e de articulação político-social existentes entre os agentes, bem como a maneira como estes se articulam no APL a fim de atingir seus objetivos, definindo, assim, a governança. Este processo foi realizado em fases, mais precisamente em três - pré-análise; exploração do material; $e$ tratamento dos resultados, a inferência e a interpretação -, conforme preconizado por Bardin (1977).

Na pré-análise foi realizada leitura flutuante e audição das informações coletadas a fim de conhecer gradativamente o conteúdo das mensagens gravadas nas entrevistas; em seguida, as respostas dos roteiros de entrevistas foram transcritas em fichas.

$\mathrm{Na}$ exploração do material as categorias definidas foram construídas a partir da ênfase em palavras e sentidos mais frequentes nas entrevistas, identificadas com o auxílio do software "Nvivo Starter Sample Project". A partir delas foi realizada a comparação de enunciados e repetições de termos, temas e frases nas transcrições das respostas dos entrevistados para, em seguida, destacá-las e separá-las para posterior análise temática e de significância.

As expressões destacadas foram agrupadas em Unidades de Contexto, também denominadas subcategorias, imperativas para a categorização dos resultados da pesquisa de modo alinhado com embasamento teórico referendado para definição da estrutura e tipo de governança no Arranjo Produtivo estudado. Assim, as categorias definidas foram: Atuação Pública, que, por sua vez, foi repartida nas subcategorias Ações e Programas, e Articulação entre Agentes, dividida nas subcategorias Confiança, Cooperação e Interação, conforme a Tabela 2. 
Tabela 2 - Categorias de análise

\begin{tabular}{|c|c|c|c|c|}
\hline $\begin{array}{l}\text { Unid. de } \\
\text { contexto }\end{array}$ & Conceito norteador & $\begin{array}{l}\text { Subcate- } \\
\text { gorias }\end{array}$ & Categorias & Unid. de registro \\
\hline $\begin{array}{l}\text { Infraestrutura do } \\
\text { APL }\end{array}$ & $\begin{array}{l}\text { Evidencia o investimento público em } \\
\text { infraestrutura no Arranjo. }\end{array}$ & & \multirow{3}{*}{$\begin{array}{l}\text { Atuação } \\
\text { Pública }\end{array}$} & \multirow{3}{*}{$\begin{array}{l}\text { A atuação pública } \\
\text { no APL deve ser } \\
\text { percebida a par- } \\
\text { tir da instituição } \\
\text { de programas e } \\
\text { ações. }\end{array}$} \\
\hline Coparticipação & $\begin{array}{l}\text { Remete à participação dos demais } \\
\text { agentes no processo de criação de } \\
\text { políticas ou planejamento de ações. }\end{array}$ & Ações & & \\
\hline $\begin{array}{l}\text { Programa de De- } \\
\text { senvolvimento }\end{array}$ & $\begin{array}{l}\text { Evidencia a existência de projetos ou } \\
\text { planos de desenvolvimento. }\end{array}$ & Programas & & \\
\hline $\begin{array}{l}\text { Confiança entre } \\
\text { agentes }\end{array}$ & $\begin{array}{l}\text { Denota comportamentos e ações de } \\
\text { confiabilidade por meio de acordos, } \\
\text { contratos e transações comerciais. }\end{array}$ & Confiança & \multirow{3}{*}{$\begin{array}{l}\text { Articulação } \\
\text { entre } \\
\text { Agentes }\end{array}$} & \multirow{3}{*}{$\begin{array}{l}\text { A forma como os } \\
\text { agentes articulam- } \\
\text {-se no APL depen- } \\
\text { derá do nível de } \\
\text { confiança, coope- } \\
\text { ração e interação } \\
\text { destes. }\end{array}$} \\
\hline $\begin{array}{l}\text { Cooperação en- } \\
\text { tre agentes }\end{array}$ & $\begin{array}{l}\text { Observa ajuda mútua, ações e van- } \\
\text { tagens coletivas. }\end{array}$ & Cooperação & & \\
\hline $\begin{array}{l}\text { Relacionamentos } \\
\text { entre agentes }\end{array}$ & $\begin{array}{l}\text { Evidencia a forma como se dão os } \\
\text { relacionamentos políticos, sociais e } \\
\text { comerciais. }\end{array}$ & Interação & & \\
\hline
\end{tabular}

Fonte: Os autores.

Na última etapa de investigação foram cumpridas a tarefa de tratamento dos resultados, a inferência e a interpretação das mensagens, momento em que foi colocada em prática a análise dos dados propriamente dita, o que permitiu conhecer, de forma mais clara e detalhada, as informações necessárias para o alcance do objetivo principal deste trabalho.

\section{CARACTERIZAÇÃO DOS AGENTES DO APL}

No APL do açaí miriense foi possível observar in loco, e confirmar por meio dos dados primários e secundários obtidos, a aglomeração de agentes econômicos, políticos e sociais, conforme sintetizado na Tabela 3.

Tabela 3 - Principais agentes que integram o APL do Açaí em Igarapé-Miri

\begin{tabular}{|c|c|c|}
\hline Agentes & Instituições & Atividades \\
\hline \multirow{7}{*}{ Econômicos } & $\begin{array}{l}\text { Produtores } \\
\text { Rurais }\end{array}$ & $\begin{array}{l}\text { São agricultores de açaí proprietários ou arrendatários de espaços } \\
\text { rurais que, de acordo com a capacidade de produção e tamanho da } \\
\text { área de cultivo, são classificados como pequenos, médios ou grandes } \\
\text { produtores. }\end{array}$ \\
\hline & Peconheiros & São trabalhadores autônomos contratados para a colheita do açaí. \\
\hline & $\begin{array}{l}\text { Indústrias de } \\
\text { Beneficiamento }\end{array}$ & $\begin{array}{l}\text { São empresas de transformação primária que processam o açaí in } \\
\text { natura transformando o fruto em polpa congelada para posterior } \\
\text { comercialização. A produção destas empresas é comercializada com } \\
\text { outras indústrias de transformação secundária com sede em outros } \\
\text { Estados do Brasil. }\end{array}$ \\
\hline & Marreteiros & $\begin{array}{l}\text { São comerciantes intermediários de açaí que se dirigem até pequenos } \\
\text { e médios produtores para comprar, em atacado, os frutos a fim de } \\
\text { revendê-los para atravessadores. }\end{array}$ \\
\hline & $\begin{array}{l}\text { Batedores } \\
\text { Artesanais }\end{array}$ & $\begin{array}{l}\text { São manipuladores de açaí que transformam o fruto em polpa para } \\
\text { comercializá-lo junto a população local. }\end{array}$ \\
\hline & Atravessadores & $\begin{array}{l}\text { Recebem o açaí comprado para fins de revenda junto as indústrias } \\
\text { de beneficiamento do fruto, tanto de Igarapé-Miri como de outros } \\
\text { municípios. }\end{array}$ \\
\hline & $\begin{array}{l}\text { Agências de } \\
\text { Fomento }\end{array}$ & $\begin{array}{l}\text { São instituições com o objetivo principal de financiar capital fixo e de } \\
\text { giro para empreendimentos rurais e agroindustriais. A agência mais } \\
\text { atuante é o Banco da Amazônia S.A. (Basa). }\end{array}$ \\
\hline
\end{tabular}




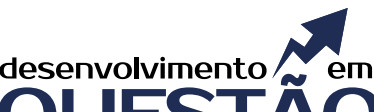

\begin{tabular}{|c|c|c|}
\hline Políticos & $\begin{array}{l}\text { Representantes } \\
\text { de Classe, } \\
\text { Prefeitura, } \\
\text { Governos } \\
\text { Estadual e } \\
\text { Federal }\end{array}$ & $\begin{array}{l}\text { Atuam na criação de políticas públicas para fins de desenvolvimento } \\
\text { local, com destaque para organizações de pesquisa e desenvolvimento, } \\
\text { assistência técnica e rural, sindicatos e o Poder Executivo nas três } \\
\text { esferas. }\end{array}$ \\
\hline \multirow{3}{*}{ Sociais } & Associações & $\begin{array}{l}\text { Associam agricultores incentivando a organização de trabalho e } \\
\text { auxiliando em questões sociais e políticas. }\end{array}$ \\
\hline & Cooperativas & $\begin{array}{l}\text { Sociedades coletivas que intervêm na comercialização do açaí } \\
\text { produzido por pequenos produtores absorvendo toda a produção a } \\
\text { fim de comercializar em atacado o açaí junto a grupos industriais locais } \\
\text { e de outros municípios do Pará, não permitindo a comercialização da } \\
\text { produção com marreteiros e atravessadores. }\end{array}$ \\
\hline & $\begin{array}{c}\text { Serviços Sociais } \\
\text { Autônomos }\end{array}$ & $\begin{array}{l}\text { São entidades paraestatais prestadoras de serviços sociais de modo } \\
\text { autônomo. Em Igarapé-Miri esta categoria é representada pela } \\
\text { atuação de basicamente três instituições: Serviço Brasileiro de } \\
\text { Apoio às Micro e Pequenas Empresas (Sebrae); Serviço Nacional de } \\
\text { Aprendizagem Rural (Senar); e Serviço Nacional de Aprendizagem } \\
\text { Industrial (Senai). }\end{array}$ \\
\hline
\end{tabular}

Fonte: Os autores.

\section{Inter-relações no APL do açaí em Igarapé-Miri}

Figura 2 - Inter-relações dos agentes do APL do açaí em Igarapé-Miri

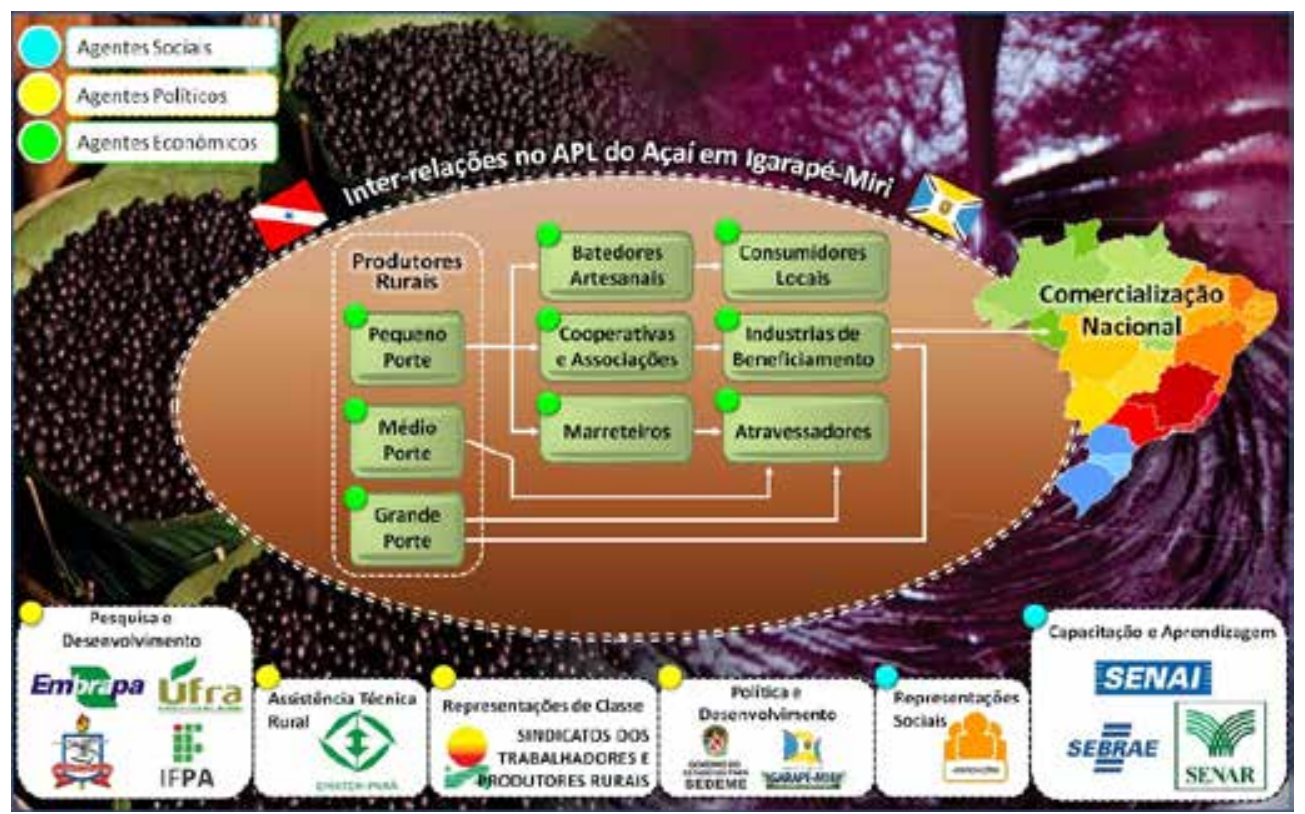

Fonte: Os autores.

\section{ESTRUTURA E TIPO DE GOVERNANÇA DO APL DO AÇAÍ EM IGARAPÉ-MIRI}

Esta seção apresenta qualitativamenteos resultados obtidos na pesquisa de campo realizada, na qual se buscou analisar e compreender o modo de atuação, relacionamento e articulação entre os agentes que representam o APL estudado, considerando que estes elementos são fundamentais para o entendimento da dinâmica territorial que revela a natureza da governança local. 


\section{Percepções dos entrevistados e análise da governança no APL do Açaí de Igarapé-Miri}

Para melhor compreensão dos depoimentos e da análise, esta subseção apresenta a caracterização das cinco pessoas entrevistadas (Tabela 4).

Tabela 4 - Caracterização dos entrevistados

\begin{tabular}{c|c|c|c|c}
\hline Identificação & Tipo de agente & Organização & Cargo/Função & $\begin{array}{c}\text { Data da } \\
\text { entrevista }\end{array}$ \\
\hline E1 & Econômico & Codemi & Presidente & $13 / 6 / 2018$ \\
\hline E2 & Político & STR & Presidente & $13 / 6 / 2018$ \\
\hline E3 & Político & Departamento de Agricultura & Diretor & $9 / 7 / 2018$ \\
\hline E4 & Econômico & Açaí Miriense & Tecnóloga de alimentos & $13 / 6 / 2018$ \\
\hline E5 & Econômico & Ex-prefeito de Igarapé-Miri & Produtor rural & $29 / 8 / 2018$ \\
\hline
\end{tabular}

Fonte: Os autores.

Na sequência serão apresentadas as percepções obtidas a partir dos depoimentos dos agentes entrevistados, tendo como base a transcrição das respostas destes e a análise interpretativa dos relatos, o que revelará a governança existente no APL pesquisado de acordo com a metodologia adotada. A análise será apresentada a partir das seguintes categorias: Atuação Pública e Articulação entre Agentes.

\section{Categoria Atuação Pública}

A seguir enfatizam-se relatos coletados nas entrevistas concernentes ao modo como a administração pública (direta e indireta, municipal, estadual e federal) e alguns entes paraestatais atuam no APL, mais precisamente: Prefeitura de Igarapé-Miri, Governo do Estado do Pará, Governo Federal, Agências de Fomento e Serviços Sociais Autônomos. Este campo evidencia a existência de projetos ou planos de desenvolvimento no Arranjo, principalmente relacionados ao investimento público em infraestrutura, além da averiguação da participação dos demais agentes no processo de criação de políticas ou planejamento de ações.

\section{Interpretação da Categoria Atuação Pública}

Os relatos indicaram inconsistente presença de instituições de pesquisa, como a Empresa Brasileira de Pesquisa Agropecuária (Embrapa) e a Universidade Federal do Pará (Ufpa). A partir dos anos 2000, quando o APL se consolidou, a atuação destas instituições diminuiu e as ações públicas de investimento no Arranjo pouco ocorreram, exceto a Empresa de Assistência Técnica e Extensão Rural (Emater), que ainda possui razoável atuação entre os produtores rurais do município, auxiliando, sobretudo, na elaboração de projetos e acompanhamento técnico. Segundo um agente político do município, "já houve um momento em que a universidade 'desceu', a Emater acompanhou... A Embrapa é um sonho. Quando o APL se consolidou, essas organizações se afastaram" (COELHO JR., 2018, p. 70). 
No âmbito municipal, a única iniciativa de maior visibilidade executada pela prefeitura consistiu na disponibilização de um terreno público localizado às margens do rio que banha a cidade, que, mesmo em condições inadequadas, serve de entreposto para escoamento da produção de açaí.

Relatos de agentes econômicos do APL ressaltam que a atuação do governo municipal deixa a desejar principalmente na atenção às necessidades infraestruturais de portos.

Com relação à infraestrutura, nós estamos trabalhando, particularmente, para meIhorar isto, nós fizemos (associação e cooperativas) 3 portos no Rio Santo Antônio, onde em cada porto, um grupo domina (usa). Aqui na cidade tem um (porto) que não é lá essa coisas. Não há investimento do governo nessa área. [...] as condições de embarque e desembarque, principalmente, nos portos do município é muito precária (COELHO JR., 2018, p. 71).

Além dessas, os agentes relatam certa ineficácia do poder público com relação à manutenção e à pavimentação de estradas e, principalmente, ramais utilizados para escoamento da produção. Na principal via de escoamento da produção, a rodovia do Açaí, porém, as pontes existentes na estrada, que antes eram de madeira, hoje estão sendo substituídas por concreto, graças ao governo do Estado do Pará, que tem contribuído nos últimos anos com algumas melhorias neste sentido, impulsionadas por emendas ao orçamento provocadas por parlamentares que atuam na região.

No que se refere ao planejamento de ações para o APL, na atual conjuntura o governo estadual lançou o "Plano Estratégico de Desenvolvimento Sustentável do Estado do Pará - Pará 2030", que, em sua fase inicial, se apresenta como uma iniciativa que visa a instituir ações planejadas a partir da participação de agentes locais, ouvidos em assembleias cujas pautas consistiram em discutir ações para o APL voltadas, especialmente, para estimular a ampliação e a verticalização da produção, por meio do plantio de açaí em terra firme e estebelecimento de indústrias de transformação secundária e terciária. Os Produtores Rurais, no entanto, não se sentem contemplados com o projeto, pois alegam que, na prática, a iniciativa visa a estimular apenas o setor industrial.

A relação entre o exposto até aqui e o que defendem Dias e Cario (2014), aponta para a conclusão de que a governança pública é ausente no APL, posto que o Estado pouco estabelece ou coordena as prioridades de todos os atores locais para a consecução de objetivos coletivos, o que é sustentado por Martins e Marini (2014), ao considerarem a ausência de governo em rede, orientado para resultados, integrando governo e atores sociais na condução de políticas públicas, negociando e harmonizando interesses.

Por isso, salienta-se que as iniciativas de desenvolvimento em voga se apresentam vestidas de exogenia, ao contrário da lógica de desenvolvimento que tornou Igarapé-Miri referência na produção de açaí, o que pode ser reflexo da baixa produção de bens ou serviços coletivos, além da fraca intercoletividade entre Estado e autoridades locais, elementos essenciais de governança pública, conforme defendem Colletis et al. (1999). 


\section{Categoria Articulação entre Agentes}

Neste tópico os relatos coletados centram-se na forma como ocorre a articulação entre os agentes, seja intragrupo seja entre categorias distintas, evidenciando a forma como se dão os relacionamentos políticos, sociais e comerciais no Arranjo, observando comportamentos e ações de confiabilidade e ajuda mútua.

\section{Interpretação da Categoria Articulação entre Agentes}

Um dos principais pilares do capital social, a confiança entre os agentes, aponta um cenário desfavorável, sobretudo no que diz respeito às relações entre os Produtores Rurais e Associações ou Cooperativas.

O baixo nível de confiabilidade entre os Produtores Rurais acarreta fortemente a queda dos atos de cooperação entre estes, seja na luta para garantir direitos sociais seja na busca de vantagens comerciais. O cooperativismo no município, que já foi muito forte há alguns anos, diminuiu gradativamente à medida que os atravessadores (depois os marreteiros) passaram a se fortalecer e aliciar, de modo mais aguerrido, os Pequenos Produtores Rurais.

A queda no cooperativismo também é atribuída à ascensão socioeconômica dos Produtores Rurais, posto que a melhoria nas condições de vida destes acarretou certo comodismo. De acordo com Araujo (2003), no entanto, a submissão dos Produtores Rurais em relação a comerciantes intermediários se deu, principalmente, em razão da desvalorização deste capital social, representado pelos baixos laços de confiança e de conexão social e pela incapacidade de cooperação e confiança mútua.

Hoje, em Igarapé-Miri, o modo de atuação dos produtores não é uniforme: muitos preferem trabalhar individualmente, com autonomia para vender a produção; enquanto outros optam pelo trabalho cooperado, vendendo a produção para as indústrias por meio de Cooperativas ou Associações.

Por outro lado, o fortalecimento econômico dos atravessadores possibilitou a criação de sólidas redes de comercialização destes com os marreteiros. O grande vulto de capital transacionado, à vista, entre esses agentes, criou um laço de confiança, ou até mesmo de fidelidade extremamente forte, ao considerar-se que grande parte dos marreteiros são fornecedores exclusivos de determinados atravessadores. Este mesmo nível de confiança existe entre atravessadores e seus clientes (as indústrias), a julgar que estas consideram aqueles como seus principais fornecedores.

A relação de confiança entre os Atravessadores e os Marreteiros é muito forte, a relação entre os Atravessadores e as indústrias também é forte, ao ponto de os Atravessadores garantirem o funcionamento das indústrias, fornecendo insumos (o açaí), quando elas estão fracas das pernas (COELHO JR., 2018, p. 74).

No APL a relação entre as indústrias locais também é alicerçada por um alto nível de confiabilidade e parceria, uma vez que estas não se veem como concorrentes, e sim como aliadas no mercado. Esta relação harmoniosa é bem-percebida no período de safra, em dias em que a produção de açaí é excessivamente alta. Quando isso ocorre, algumas indústrias locais, com menor capacidade de processamento, encaminham seus frutos in natura para serem processados em outras unidades. 
As relações entre comerciantes intermediários e destes com o setor industrial é coesa. Neste grupo, os membros demonstram confiabilidade e depositam ampla confiança uns nos outros, possibilitando realizar muito mais do que o outro grupo (dos produtores rurais) que carece de confiança. O patrimônio intangível que representa esta relação é definido pela interação que promove o dinamismo, alavanca a produção e a produtividade e a capacidade do grupo para conquistar soluções a partir de estratégias "ganha-ganha" (VIANA et al., 2016; PAIVA, 2004; COLEMAN, 1990 apud PUTNAM, 1996).

Do ponto de vista político, o relacionamento entre os agentes é caracterizado pela má interação envolvendo a Prefeitura, o governo do Estado e os demais. A conjuntura atual indica que o bom diálogo entre o poder público e os agentes privados do Arranjo é oscilante, pois a posição político-partidária de alguns pode facilitar ou atravancar negociações, o que demonstra que os agentes governamentais, atuantes no APL, não possuem sólida relação com os demais agentes locais.

Compreende-se, portanto, que, no APL analisado, o conceito de governança, defendido por Cassiolato e Lastres (2003b) e Loffer (2001 apud KISSLER, HEIDEMANN, 2006; GONÇALVES, 2006), é pouco exercido, em virtude do baixo nível de ações governamentais descentralizadas e parcerias entre o público e o privado, bem como são baixos os mecanismos de coordenação e negociação entre atores sociais visando a soluções para o desenvolvimento dos participantes do Arranjo.

De outra forma, a interação entre os agentes privados do Arranjo é bastante intensa e, dependendo do ângulo, pode se mostrar harmoniosa ou conflituosa. Em termos comerciais, a interação entre marreteiros, atravessadores e indústrias de beneficiamento é bem-construída, definida por uma estrutura de governança que vai ao encontro do que preconizam Justen et al. (2015), pois este grupo de agentes atua no sistema produtivo estabelecendo laços de interação, criando mecanismos de coordenação e controle do ambiente, por meio de práticas de cooperação para a solução de problemas comuns para que seja alcançado o sucesso de suas atividades.

Por outro lado, o nível de organização dos produtores rurais e as relações destes com seus clientes, principalmente os atravessadores e o setor industrial, demonstra sinais de instabilidade, em razão de uns conflitos de interesses relacionados ao preço de compra e venda do açaí. A maior contestação dos produtores, Cooperativas, Associações e Representações Sindicais consiste no fato de o setor industrial determinar o preço de compra do açaí produzido, institucionalizando uma regra que versa no estabelecimento de um preço de compra uniforme para todas as indústrias que adquirem açaí em Igarapé-Miri; preço este que nos últimos anos tem caído consideravelmente, impactando na lucratividade dos produtores Rurais.

O cenário ora estabelecido indica que a articulação entre os produtores rurais e seus clientes está na contramão da definição de governança de Fuini (2014), considerando-se que, no APL do açaí estudado, as ações tornaram-se menos coletivizadas, provocando a diminuição da coordenação de iniciativas que busquem a viabilização de interesses comuns, resultando em um ambiente em que as relações não contribuem para a melhoria da competitividade para todo o conjunto do Arranjo. 


\section{Implicações para o Desenvolvimento Local}

Os dados coletados possibilitaram constatar o enfraquecimento de ações conjuntas, mecanismos de coordenação e negociação entre agentes, criando possibilidades de interação e desenvolvimento para todos os participantes, conforme apregoam Cassiolato e Lastres (2003b), Kissler e Heidemann (2006) e Gonçalves (2006).

A ausência de alguns fatores essenciais para a boa governança contribui fortemente para o contexto atual, entre os quais destaca-se o declínio na organização social representada pela deterioração ou, em muitos casos, ausência de mecanismos de articulação entre produtores rurais e destes com os movimentos políticos e sociais, demonstrando uma significativa desvalorização e desarticulação do capital social rural, traduzida pelo baixo nível de confiança, solidariedade, integração social, cooperação e coparticipação.

Por outro lado, ao considerarmos que a atuação de atores não estatais é central para o desenvolvimento da ideia e da prática da governança (GONÇALVES, 2006) e que os problemas mais emergenciais da sociedade são em decorrência da falta ou ineficácia na participação do Estado (ULTRAMARI; DUARTE, 2011, p. 32), compreende-se que a queda na atuação governamental nos últimos anos, em conjunto com indivíduos e organizações públicas e privadas, no sentido de promover e sustentar o crescimento do APL, contribuiu para o surgimento de ingerências de problemas comuns e acomodação de interesses conflitantes.

Além do mais, ao considerarmos que no APL em análise, ou em qualquer outro, a estrutura de governança é representada pelas forças organizacionais e institucionais e que estas são capazes de condicionar o comportamento dos agentes no Arranjo (JUSTEN et al., 2015 ), destacam-se os mecanismos de articulação construídos por marreteiros, atravessadores e indústrias de beneficiamento, em que estes se valem de uma "falha de governança" no APL como um todo para usufruir, estrategicamente, de uma estrutura de governança "privada" que abrange a capacidade de reação coletiva às ameaças e oportunidades, a ponto de garantir o triunfo econômico do grupo, oportunizada pela capacidade de determinação de preços e aumento de ganhos em escala. Ou seja, os agentes econômicos, detentores de altos volumes de capital, desenvolvem mecanismos de "rent seeking". Sobre esse ponto, os resultados obtidos revelam que o reduzido número de indústrias de beneficiamento, detentoras de ativos estratégicos de natureza tecnológica, comercial, produtiva ou financeira, em contraste com o expressivo contingente de produtores e de produção, abre espaço para a ocorrência de uma estrutura de mercado caracterizada por uma competição imperfeita, em que existem poucos compradores (indústrias) e muitos vendedores (produtores rurais).

Esse fenômeno estrutural mercadológico nos leva a concluir que no Arranjo Produtivo Local do Açaí em Igarapé-Miri, conforme preconizam Colletis et al. (1999), na atual conjuntura, a governança é Privada, uma vez que um número reduzido de agentes privados domina e conduz mecanismos de coordenação e criação de recursos com vistas a atender seus próprios interesses, influenciando significativamente a forma de atuação dos demais agentes existentes no APL e, simultaneamente, desestimulando o 
desenvolvimento econômico local endógeno, uma vez que a governança em voga consiste em um processo que não promove a melhoria da qualidade de vida e o bem-estar da população local, principalmente dos produtores rurais.

\section{CONSIDERAÇÕES FINAIS}

Neste artigo, o conceito de Arranjo Produtivo Local foi considerado uma das maneiras de contribuição para o desenvolvimento por meio da organização de atores locais reunidos em redes de relacionamento, o que ensejou a abordagem da governança entendida aqui como a arte de mobilizar e coordenar ações coletivas, de modo a dinamizar potencialidades capazes de consolidar e fortalecer o APL.

As referências teóricas que embasaram este trabalho foram essenciais para o alcance do objetivo proposto. Isto foi fundamental para demonstrar, por intermédio de fatos, como a governança pode ser estruturada e exercida na prática, o que contribuiu também para a compreensão de como a caracterização dos agentes do Arranjo e suas inter-relações são adequadas para abrirem caminhos que levam à descoberta da natureza da governança existente no APL do açaí em Igarapé-Miri.

A importância do trabalho reside em apontar os entraves para a governança horizontal em sistemas de produção local voltados a produtos oriundos da diversidade natural na região amazônica. Mesmo no caso do açaí, normalmente retratado como um exemplo de sucesso, verifica-se grandes dificuldades do coordenação entre os produtores rurais.

Por meio da metodologia adotada, os dados coletados e analisados mostraram que a forma como o Arranjo está estruturado e o modo de atuação de seus agentes indicam que o tipo de governança existente no APL do açaí no município de Igarapé-Miri é do tipo Privada, caracterizada pelo fraco desempenho governamental e pela atuação estratégica de agentes industriais bem-articulados com seus principais fornecedores, os atravessadores, além do baixo nível de coparticipação, cooperação e associativismo, o que demonstra que as estruturas de governança construídas estão em processo de declínio (ou transformação) em razão da sobreposição de ações de iniciativas individuais, da inexpressiva participação e atuação governamental e do enfraquecimento dos movimentos sociais.

No âmbito acadêmico, o presente estudo oportunizou breve revisão teórico-conceitual realacionada a APLs e Governaça como forma de apresentar a correlação entre esses temas, bem como a implicação dos mesmos para o desenvolvimento de pequens territórios.

O trabalho realizado apresentou uma limitação considerável: a dificuldade de acesso aos agentes públicos do Poder Executivo do município investigado, principalmente aos que atuam em nível estratégico, como prefeito e secretários.

Por fim, com o intuito de ampliar o escopo sobre este estudo, sugere-se, como futuras pesquisas, a análise mais abrangente envolvendo outros APLs do município e a investigação dos impactos ambientais e alterações socioculturais decorrentes da monocultura do açaí no Estado do Pará. 


\section{REFERÊNCIAS}

ANTERO, C. A. S. et al. Participação no processo decisório do APL de vestuário de Muriaé-MG. Revista de Gestão, v. 23, n. 3, p. 246-253, 2016.

APOLINÁRIO, V.; SILVA, M. L. da. Saber local e interações no APL de bordados de Caicó, RN: Arte-negócio no semi-árido nordestino. In: CASSIOLATO, J. E.; MATOS, M. P. de; LASTRES, H. M. M. (org.). Arranjos produtivos locais: uma alternativa para o desenvolvimento: criatividade e cultura. Rio de Janeiro: E-Papers, 2008.

ARAUJO, Maria Celina D'. Capital social. Rio de Janeiro: Passo-a-Passo, 2003.

BARDIN, L. Análise de conteúdo. Lisboa: Edições 70, 1977.

BARQUERO, A. Desenvolvimento endógeno em tempos de globalização. Porto Alegre: Editora UFRGS, 2002.

BOTELHO, J. B. L. R.; CAMPOS, Índio. Arranjo produtivo local de fitoterápicos em Manaus. In: CAMPOS, Índio (org.). Arranjos produtivos locais na Amazônia Legal. Belém: Ufpa; Naea, 2009.

BUARQUE, S. C. Construindo o desenvolvimento local sustentável. Rio de Janeiro: Garamond, 2002.

CAMPOS, M. B. Mudanças na administração pública e inserção de agentes catalisadores: o caso da Fundação Luís Eduardo Magalhães. 2002. 184 f. Dissertação (Mestrado em Administração) - Escola de Administração, Universidade Federal da Bahia, Salvador, 2002.

CASSIOLATO, J. E.; LASTRES, H. M. M. O foco em arranjos produtivos e inovativos locais de micro e pequenas empresas. In: LASTRES, H. M. M.; CASSIOLATO, J. E.; MACIEL, M. L. (org.). Pequena empresa: cooperação e desenvolvimento local. Rio de Janeiro: Relume Dumará, $2003 a$.

CASSIOLATO, J. E.; LASTRES, H. M. M. Glossário de arranjos e sistemas produtivos e inovativos locais. Rede de Pesquisa em Sistemas Produtivos e Inovativos Locais (Redesist). Nov. 2003b. Disponível em: www. ie.ufrj.br/redesist/P4/textos/Glossario.pdf. Acesso em: 28 fev. 2018.

COELHO JR., F. P. Estrutura de governança no arranjo produtivo local do açaí no município de lgarapé-Miri. 2018. 95 f. Dissertação (Mestrado em Gestão Pública) - Universidade Federal do Pará, Núcleo de Altos Estudos Amazônicos, Belém, 2018.

COLLETIS, G. et al. Construction territoriale et Dynamiquesproductives. Revue Sciences de la Societé, Tolouse, n. 48, Oct. 1999.

COSTA, E. J. M. da. Arranjos produtivos locais, políticas públicas e desenvolvimento regional. Brasília: Mais Gráfica, 2010.

D’ASCENZI, L.; LIMA, L. L. Análise de impacto "ex ante" de políticas públicas: desafios de uma agência reguladora no desenvolvimento local. Revista Interdisciplinar de Gestão Social, v. 8, n. 2, p. 87-113, 2019.

DIAS, T.; CARIO, S. A. F. Governança pública: ensaiando uma concepção. Contabilidade, Gestão e Governança, Brasília, v. 17, n. 3, p. 89-108, set./dez. 2014.

FUINI, L. L. A governança em arranjos produtivos locais (APLs): algumas considerações teóricas e metodológicas. Revista Geografia, Londrina, v. 23, n. 1, p. 57-83, 2014. Disponível em: www.uel.br/portal/frm/ frmOpcao.php?opcao=http://www.uel.br/revistas/uel/index.php/geografia. Acesso em: 13 mar. 2018.

GONÇALVES, A. O conceito de governança. CONPEDI, 2006, Manaus. Anais [...]. Manaus, 2006. Disponível em: http://www.conpedi.org.br/manaus/arquivos/Anais/Alcindo\%20Goncalves.pdf. Acesso em: 23 out. 2017.

JUSTEN, G. S. et al. Estruturas de Governança em Arranjos e Sistemas Produtivos Locais: o caso do Projeto Reca. Revista Organizações em Contexto, v. 11, n. 21, p. 101-126, 2015.

KISSLER, L.; HEIDEMANN, F. Governança pública: novo modelo regulatório para as relações entre Estado, mercado e sociedade? Revista de Administração Pública, v. 40, n. 3, p. 479-499, 2006.

MATOS, F.; DIAS, R. Governança pública: novo arranjo de governo. Campinas: Editora Alínea, 2013.

MARTINS, H. F.; MARINI, C. Governança pública contemporânea: uma tentativa de dissecação conceitual. Revista do Tribunal de Contas da União, v. 46, n. 130, p. 42-53, maio/ago. 2014.

PUTNAM, R. D. Comunidade e democracia: a experiência da Itália moderna. Rio de Janeiro: Fundação Getúlio Vargas, 1996.

SOUZA FILHO, J. R. Desenvolvimento regional endógeno, capital social e cooperação. Porto Alegre: UFRGS, 2002. (Mimeo.).

TAPIA, J. R. B. Desenvolvimento local, concentração social e governança: a experiência dos pactos territoriais na Itália. São Paulo em Perspectiva, v. 19, n. 1, p. 132-139, jan./mar. 2005.

ULTRAMARI, C.; DUARTE, F. Desenvolvimento Local e Regional. Curitiba: Editora Ibpex, 2011. 